\title{
Abstract \\ Management of Urinary Tract infections in Children: Compliance with the National Institute for Health and Care Excellence (NICE) guidelines?
}

Sivalingam $\mathrm{J}^{1^{*}}$, Ikpakwu $\mathrm{E}^{2}$, Liyanage $\mathrm{G}^{3}$

${ }^{1}$ Teaching Hospital Jaffna, Sri Lanka

${ }^{2}$ Bronglais GH, United Kingdom

${ }^{3}$ Colombo South Teaching Hospital, Kalubowila

\begin{abstract}
Background

Urinary tract infections (UTI) are common among children. Management of UTI requires prompt diagnosis, treatment and most often, a regular follow up. Objective of the study was to evaluate compliance with the NICE guidelines 2007 when managing children with UTI at Bronglais General Hospital, Aberystwyth, United Kingdom.

Method

Study design was descriptive, retrospective and single centered study. Study population was 96 children aged 0 to16 year managed at above hospital during 2012 to 2014 period with confirmed UTI.

\section{Results}

Only $25 \%$ of infants less than 3 months old received intravenous antibiotics, deviating from the guidelines. Majority had oral only $(25 \%)$ or intravenous followed by oral antibiotics $(50 \%)$. For treatment of lower tract infection, duration of antibiotics prescription was longer than recommended. Overall adherence to investigations such as ultrasonography (USS), DMSA and Micturating Cysto-urethrogram (MCUG) was $81 \%$, 91\% and 93\% respectively. All children with recurrent UTIs were prescribed antibiotic prophylaxis adhering to NICE guidelines.

\section{Conclusions}

This study highlights the disparity in the management of UTI in children despite established guidelines.
\end{abstract}

Key words: Urinary tract infections; Antibiotics; Investigation

Copyright:@ 2015 Aluvihare S et al. This is an open access article distributed under the Creative Commons Attribution License, which permits unrestricted use, distribution, and reproduction in any medium, provided the original work is properly cited.

*Correspondence : dr_sbalan@yahoo.com

Cite this abstract as: Sivalingam $\mathrm{J}^{1}$, Ikpakwu $\mathrm{E}^{2}$, Liyanage $\mathrm{G}^{3}$. Management of Urinary Tract infections in Children: Compliance with the National Institute for Health and Care Excellence (NICE) guidelines?. Anuradhapura Medical Journal 2015;9 (2Supp):S42.

DOI: http://dx.doi.org/10.4038/amj.v9i2Supp.7591 


\section{Submit your next Manuscript to} Anuradhapura

Submit your manuscript at http://amj.sljol.info/ 